\title{
Chacal ou Cordeiro? O Brasil frente aos desafios e oportunidades do Sistema Internacional ${ }^{1}$
}

\author{
Jackal or Lamb? Brazil in face of the challenges \\ and opportunities of the International System
}

JÚLIO CÉSAR COSSIO RODRIGUEZ*

Rev. Bras. Polít. Int. 55 (2): 70-89 [2012]

\section{Introdução}

Este artigo analisa os efeitos estruturais do Sistema Internacional (SI) sobre os Estados a partir do caso brasileiro. O estudo recente de Octávio Amorim Neto (2011) sobre as "determinantes e condicionantes da Política Externa Brasileira no período de 1945 até 2008” afirma que uma variável neorrealista ou sistêmica é a mais relevante para analisar a condução da política externa do Brasil. Assim, a partir dessa afirmação iremos analisar os cenários e projeções de política externa do Brasil. Quais são as adaptações da política externa brasileira às mudanças estruturais em curso no sistema internacional? Nesse cenário de transição o Brasil configura-se como grande potência revisionista, isto é, como um Leão no SI? Ou quer atuar como Leão, porém está mais para Chacal ou Cordeiro, segundo as categorizações utilizadas por Randall Schweller (1994, 1998)?

As análises sobre a emergência do Brasil como global player ou ainda como potência regional (polo de poder) estão relacionadas com o relativo crescimento de suas capacidades materiais (principalmente econômicas), mas também com o crescimento da sua participação nas relações internacionais. (Hurrell 2010; Flemes 2010a; Soares de Lima e Hirst 2006). A expansão da política externa do Brasil, com uma atuação global (Villa e Viana 2010; Soares de Lima e Hirst 2006) e com a diversificação em "eixos" de inserção internacional (Pecequilo 2008; Visentini e Reis da Silva 2010) pode ser, portanto, o resultado de condicionantes sistêmicas ou estruturais em função do crescimento das suas capacidades materiais ou da redistribuição delas ao nível global.

1 O Autor agradece os comentários e sugestōes de Andrés Malamud ao original deste artigo.

* Bacharel em Relaçóes Internacionais pela Universidade Federal do Rio Grande do Sul (UFRGS). Mestre em Ciência Política pela Universidade Federal do Rio Grande do Sul (UFRGS). Doutorando em Ciência Política pela Universidade de Lisboa (juliocossio@gmail.com). 
Os trabalhos mais importantes sobre as relações internacionais do Brasil relacionam-se, em sua maioria, com variáveis explicativas de $1^{\text {a }}$ e $2^{\text {a }}$ imagem, isto é, remetem-se ao nível dos Indivíduos (por exemplo, Lideranças Políticas, Ministros, Chanceleres) e do Estado (por exemplo, Burocracia Estatal, Força Parlamentar). (Almeida 2004; Cervo 2003, 2010; Fonseca Jr 2011). A relevância da estrutura internacional, ou seja, de uma variável explicativa derivada da $3^{a}$ imagem e suas possíveis modificações recentes, notadamente a partir da emergência chinesa, são por vezes negligenciadas, principalmente, pelo peso excessivo dado aos formuladores internos da política externa, em especial ao poder Executivo.

Neste estudo define-se como principal condicionante da política externa do Brasil a estrutura do sistema internacional e suas mudanças recentes. (Amorim Neto 2011). Iremos considerar a existência de relação causal entre a estrutura do SI e os Estados, em função de suas capacidades materiais. Estas constituem a base do tamanho de poder que concentra um Estado no sistema internacional anárquico. (Waltz 1979, 2000). Consoante a isso relacionaremos as capacidades materiais com os derivados constrangimentos ao qual estão submetidos os Estados, bem como com as possibilidades de atuação que derivam desse relacionamento. (Schweller 1994, 2004; Mearsheimer 2001; Wohlforth 1999). Pretende-se demonstrar, enfim, que as opções estratégicas de um Estado relacionam-se diretamente com a estrutura internacional e com o poder que concentra no sistema internacional. Assim, opta-se primeiramente por analisar, a partir do neorrealismo, a atual configuração do sistema internacional, que pode ser definida tanto como uma Unipolaridade Estável (Wohlforth 1999) quanto como por uma Multipolaridade Desequilibrada (Mearsheimer 2001; Cepik e Schneider 2010; Schweller e Pu 2011). Complementarmente será realizado um balanço das reais capacidades materiais do Brasil (Econômicas e Militares) que permitam analisar se os objetivos propostos pelo país em sua grande estratégia são alcançáveis por meio de sua operacionalização. Portanto, o objetivo deste artigo é complementar as análises que são produzidas sobre a atuação do Brasil no Sistema Internacional por meio de uma análise que se baseia, principalmente, no Realismo pós-Waltziano (Moure Peñin 2009), conforme sugere Amorim Neto (2011).

Assim será realizada uma abordagem em três partes. Primeiro, uma análise sobre a configuração do Sistema Internacional a partir da perspectiva Neorrealista. Segundo, em um exame sobre os principais aspectos recentes da política exterior do Brasil para a região e para o mundo. Na terceira parte será feito um balanço sobre as capacidades materiais do Brasil para poder inferir quais são os efeitos da estrutura internacional sobre uma potência emergente. A principal hipótese, portanto, a ser analisada neste artigo é de que os objetivos da política exterior do Brasil estão condicionados pelas suas capacidades materiais na relação com as mudanças recentes na estrutura do Sistema Internacional. 


\section{O Sistema Internacional em transição}

A configuração atual do sistema internacional é objeto de grande debate no campo da política internacional. A teorização principal sobre esse tema é feita por Kenneth Waltz, em 1979, no livro Theory of International Politics, obra que inaugura o chamado Realismo Estrutural, Sistêmico ou ainda o Neorrealismo. (Cepik e Schneider 2010). Iniciaremos a análise pela exposição dos principais pressupostos teóricos sobre o sistema internacional, com base em Waltz, seus críticos e seguidores. Portanto, o primeiro deles versa sobre quais são os principais atores internacionais, ou seja, aqueles que serão analisados pelo campo de estudos da política internacional. Waltz (1979) afirma que são os Estados os atores principais do sistema internacional; essa premissa basilar está presente nos principais autores que se relacionam com o neorrealismo, segundo balanço feito por Moure Peñin (2009).

A segunda premissa definida por Waltz (1979) é de que o Sistema Internacional é Anárquico, ou seja, há ausência de governo central. Essa premissa está relacionada com a caraterística funcional dos Estados, pois são estes dotados de iguais funções e podem ser considerados atores independentes e soberanos. Essa independência funcional, que confere ao Estado o papel de protagonista no sistema internacional e determina a sua forma de organização, se relaciona com a terceira premissa do realismo estrutural, isto é, de que os Estados são atores racionais. Implica afirmar que sua atuação está relacionada diretamente com os objetivos que definem em sua política exterior. Por fim, é possível definir a última premissa básica do realismo estrutural, ou seja, de que os Estados perseguem seus interesses definidos em termos de poder. Destaca-se, contudo, que apenas a primeira e a terceira premissas são compartilhadas de forma geral pelos trabalhos posteriores do realismo estrutural (Moure Peñin 2009), enquanto, por exemplo, o realismo neoclássico - em especial Schweller (2003) -, interpreta que Waltz não categoriza os Estados como atores racionais (Elman e Elman 2003).

Todavia, a segunda e a quarta premissas são objetos de grandes debates teóricos dentro do neorrealismo. É a partir da última premissa que decorre a divisão em torno dos neorrealistas ofensivos e defensivos. Os primeiros afirmam que os Estados perseguem objetivos de poder; já os segundos defendem que os Estados perseguem interesses em termos de segurança. A partir dessa divisão podemos identificar quais são as recentes divisões do neorrealismo entre os autores. Kenneth Waltz, com suas hipóteses principais, está inserido dentre os autores clássicos do realismo estrutural defensivo, pois em sua obra afirma que os Estados buscam garantir a sua sobrevivência no sistema internacional, o que representa uma busca contínua por segurança. Enquanto isso, John J. Mearsheimer (2001) pode ser considerado o principal teórico do realismo estrutural ofensivo, quando afirma que os Estados perseguem a maximização de poder no sistema internacional e, por meio da conquista da hegemonia mundial - fim último dessa busca por poder -, 
garantirem a sua sobrevivência. Como consequência dessas definições teóricas a cooperação altruísta entre os Estados não é opção válida para o realismo estrutural, porque os interesses dos Estados enquanto atores racionais que buscam poder ou segurança impedem que isso seja possível no sistema internacional anárquico. Assim o relacionamento esperado dos Estados no SI é a competição, seja ela por segurança ou por poder. Após destacar as principais premissas do neorrealismo podemos definir algumas características teóricas da Estrutura do Sistema Internacional. Segundo Waltz (1979, 100-101):

Structures are defined, first, according to the principle by which a system is ordered [...]; second, by the specification of functions of differentiated units [...]; third, by the distribution of capabilities across units.

Como já fora definido, o princípio que ordena as unidades, os Estados, é a Anarquia. Ainda, segundo Waltz (1979), não há diferenciação entre as unidades, ou seja, os Estados são semelhantes em termos funcionais. No entanto, há a distribuição de capacidades materiais entre as unidades e esta é fundamental na definição das mudanças do Sistema Internacional e, principalmente, para a definição dos polos de poder. O que varia, consequentemente, no sistema internacional é a distribuição de capacidades entre os Estados e a partir desta é que se pode identificar qual a configuração estrutural do sistema internacional. Os Estados, enfim, têm semelhanças funcionais segundo essa definição teórica; porém, o que os diferencia são os meios materiais que serão utilizados para realização de tarefas semelhantes.

Atualmente os estudos sobre a distribuição de capacidades fazem uso de um conjunto maior de dados e problematizações. A inserção de novos critérios para definição de capacidades é uma das principais vertentes desse debate, principalmente, porque se preocupam com as razôes da manutenção da unipolaridade no pós-Guerra Fria. No entanto, os teóricos tradicionais do neorrealismo, como Waltz e Mearsheimer, defendem o uso de critérios mais simples e objetivos, isto é, medidas de poder econômico e militar. No estudo de Amorim Neto (2011) sobre a política externa do Brasil, o autor opta por considerar, também, critérios parcimoniosos, em acordo com Waltz, e para isto recorre aos dados sobre capacidades nacionais do Composite Index of National Capability (CINC) do The Correlates of War Project 2 .

A expansão do poder dos EUA no decorrer do século 20 até a virada dos anos 2000 conduz os analistas a pensar sobre a condição de primazia dos EUA, principalmente pela concentração de capacidades materiais. Nesse contexto, figuram os trabalhos de Wohlforth e Brooks (2005) e Wohlforth (1999, 2009) sobre a estabilidade e a durabilidade da atual configuração Unipolar. No entanto, essa diferença de poder material entre a potência unipolar e os outros Estados não explica totalmente a condição de primazia dos EUA, por isso os autores somam a essas

2 Disponível em <http://www.correlatesofwar.org>, acessado em 18 jun. 2011. 
definições aspectos sobre as intençōes "benignas" da potência unipolar, bem como afirmam que a manutenção dos fatores estabilizadores do sistema internacional como, por exemplo, a concentração do poder nuclear e o avanço da globalização sob sua liderança - favorece a manutenção da unipolaridade. Em acordo com essa perspectiva o comportamento a ser esperado pelos Estados é o Bandwagoning, ou seja, seguir a potência unipolar, pois os custos de fazer o balanço ou equilibrar a distribuição desigual de capacidades são muito elevados. Wohlforth e Brooks (2005) afirmam que a estrutura do sistema internacional não se modificou com o crescimento dos atores emergentes e que ainda são Hard Times for Soft Balancing. Por outro lado, Cepik e Schneider (2010) destacam que a extensão demasiada da superpotência conduzirá a formação de equilíbrios no sistema internacional, pois os custos da gestão e da distribuição desigual de capacidades afetam os atores interessados no revisionismo.

A definição de que a configuração do sistema internacional é Unipolar e duradoura não é pacífica, pois tanto Waltz quanto Mearsheimer não pactuam, em termos teóricos, dela. A unipolaridade é transitória por coerência teórica com a balança de poder, afinal para Waltz a formação de equilíbrios é, também, característica fundamental e constante do sistema internacional. As abordagens em favor da unipolaridade destacam, em sua maioria, a diferença de poder entre os EUA e o resto; o tamanho dessa diferença em conjunto com os fatores estabilizadores são suficientes para demonstrar a primazia deste em relação aos outros países. Contudo, ao analisar critérios "compromissados" (Cepik e Schneider 2010) com o realismo estrutural podemos notar que os EUA ainda não detêm a primazia nuclear (Cepik, Ávila, Martins 2009) nem espacial. (Cepik 2011).

Assim, embora os EUA apresentem um acúmulo de capacidades que não pode ser atingido, podemos inferir que pode ser contraposto com a união de outras grandes potências (Schweller 1998) - no caso atual, China e Rússia. Dessa forma, a tendência unipolar ou ainda de "congelamento do poder" internacional se rompe a partir das emergências chinesa e indiana e da recuperação russa, em diversos aspectos, mas principalmente militares e econômicos, e que conferem ao sistema uma tendência transicional para uma configuração de Multipolaridade Desequilibrada (Cepik e Schneider 2010).

Cabe, enfim, destacar que essa redistribuição das capacidades no Sistema Internacional afeta não apenas as grandes potências e sua busca por poder, mas também as potências regionais, emergentes ou médias. Os constrangimentos às grandes potências são mais notórios devido aos interesses revisionistas; porém, quais as implicações aos novos atores emergentes do SI?

Antes, porém, é necessário ressaltar que Waltz não elaborou uma teoria da política externa ou que se propunha a analisar a formulação dela pelos Estados. Assim, iremos recorrer aos estudos de outros autores, como Schweller (1998), que permitem identificar a estrutura do SI como variável independente e que afeta a todos os atores, porém incluem em suas análises aspectos relevantes para o estudo 
de caso proposto aqui, como, por exemplo, alguns aspectos internos aos Estados e sobre a percepção de capacidades materiais.

A segunda parte deste artigo irá analisar alguns aspectos sobre a política externa do Brasil, em especial as mudanças dos anos recentes (pós-2002) para poder relacionar com o relativo crescimento das capacidades do Brasil. O objetivo será identificar a dinâmica relacional entre a estrutura e a capacidade de atuação dos atores emergentes no jogo das grandes potências.

\section{Política Externa do Brasil pós-2002: aproveitando oportunidades sistêmicas?}

É em consonância com as modificações estruturais que será realizada a analise da política externa brasileira, pois, sem a compreensão dos constrangimentos e condicionantes do Sistema Internacional, a análise da política externa fica parcial. A recente política externa brasileira configura-se por algumas modificaçôes relevantes. A primeira e principal delas se refere à região. É destinada uma maior ênfase discursiva e prática à região Sul-Americana. Como destacam Spektor (2010) e Couto (2007), a mudança com relação à regiāo esteve mais presente na última década, principalmente como forma de garantir ganhos para a Política Externa do Brasil, ou seja, destaca que a região passa a ser interpretada a partir de cálculos de poder e que pode vir a servir como "trampolim" para o País. Soares de Lima e Hirst (2006, 29-30) também notam mudanças na prática política do Brasil com relação à América Latina, que passa a ser substituída pelo termo América do Sul: "Brazil’s identify as a Latin American country has therefore been increasingly replaced by the idea of the country as a South American power." Além disso, conforme Visentini e Reis da Silva (2010), a política externa do País torna-se "ativa e afirmativa" e com quatro eixos principais de inserção internacional: "(a) South America; (b) the commitment to multilateralism in the process of peace development; (c) the affirmative commercial agenda; and (d) diversified partnership with developed and developing countries."

Nota-se, então, a relevância que é dada pelo Brasil na última década ao ambiente regional em que se insere. A substituição do conceito de América Latina pelo de América do Sul, portanto, relaciona-se com os objetivos de projeção de poder no Sistema Internacional do Brasil, mas também orienta as novas iniciativas de cooperação regional, como ficou evidente após a criação da União das Nações Sul-Americanas (Unasul) e do Conselho de Defesa Sul-Americano (CDS). Ainda, conforme Rafael Villa e Manuela Viana (2010), a América do Sul esteve sempre on the top na agenda de política externa do País; no entanto, o bilateralismo era a forma prioritária de relação entre os Estados da região. Isso se modifica com a criação da Unasul, pois representa, segundo Villa e Viana $(2010,100)$, "i) rupture with the bilateralism that has prevailed up to that moment in South American 
countries intra-regional relations; and ii) rupture with the priority given to trade in previous integration processes developed within the region."

Além do mais, a associação entre os eixos "verticais e horizontais" e o rompimento com a "primazia" das relações entre o Brasil, os Estados Unidos e a União Europeia permitiram a ampliação da inserção do País nas relações internacionais contemporâneas. (Pecequilo 2008). A cooperação Sul-Sul é um desses eixos (Soares de Lima 2005, Flemes 2010b), no qual se relaciona primordialmente com os países do IBAS (ou seja, Índia e África do Sul), mas também propõe uma agenda diferenciada para o conjunto dos países africanos. (Saraiva 2010). Do mesmo modo, a ênfase no multilateralismo relaciona-se com aquilo que chamam Visentini e Reis da Silva (2010) de "geometria variável", no qual se inserem os vários Grupos que o país integra e por vezes tenta liderar. Amorim Neto $(2007,3)$ destaca alguns "ganhos" da Política Externa do Brasil:

[...] a liderança do G-20; o ativismo na América Latina, cujo grande exemplo é o envio de uma força de paz ao Haiti; o aumento do fluxo comercial na América do Sul; o avanço da interconectividade da região centrada na questáo da energia e o reforço das relações com outras grandes nações do eixo Sul-Sul (Índia e África do Sul).

No segundo mandato do Governo Lula ocorre, como destacam Villa e Viana (2010), portanto, a "mundialização" da política externa do País com novos alcances e novos desafios inerentes à ampliação da presença do País no mundo. Essas mudanças acompanham a identificação da necessidade de "gerir" a região em que se insere, para por fim configurar-se como um Polo de Poder Regional e eventual líder regional. É notável, portanto, que nos últimos anos ocorreram inúmeros ganhos ao País oriundo do sucesso econômico, da estabilidade política e de uma política externa "assertiva". (Visentini e Reis Da Silva 2010; Amorim Neto 2011). Não obstante, é necessário verificar a capacidade real do País de buscar seus objetivos e, principalmente, realizar a gestão de sua região. Isso afeta decisivamente a consolidação do Brasil como polo de poder mundial por meio da liderança na região Sul-Americana. (Malamud 2011). Ademais, os ganhos e oportunidades não podem ser entendidos apenas por meio do voluntarismo político, mas sim pela sua relação com as mudanças estruturais em curso que abrem espaço ao protagonismo de atores de médio alcance, como o Brasil.

Desse modo, conforme Amorim Neto $(2007,4)$ a diplomacia do governo Lula também teve fracassos importantes:

O Brasil não teve o apoio nem de seus principais parceiros latino-americanos nem da China para ganhar um assento no Conselho de Segurança da ONU. Os parceiros latino-americanos também não apoiaram a candidatura do Brasil no seu pleito pela direção geral da OMC. Os parceiros latino-americanos também não apoiaram a candidatura do Brasil para a presidência do BID [...]. 
Com ênfase em aspectos que podem ser considerados Soft Power (Nye 2004), os ganhos relativos ofuscam as novas demandas ao País que surgem com o ganho de poder no sistema internacional por meio da atual redistribuição de capacidades. Derivam dessa "nova etapa" estrutural e da política externa as configurações do Brasil como um Ator Intermediário (Soares de Lima e Hirst 2006), Estado periférico (Alsina Jr 2009; Guimarães 2001), Potência Regional (Nolte 2006; Flemes 2010a) ou ainda como Middle Power (Sennes 1998; Flemes 2009).

A inserção do Brasil no sistema internacional relaciona-se com a ampliação da agenda e maior participação multilateral, mas também com a percepção do tipo de "poder" que concentra no Sistema Internacional. Esse debate é desenvolvido por Daniel Flemes (2010a), que afirma que o Brasil é uma Potência Regional e um ator médio no mundo. Disso decorrem algumas considerações relevantes. A primeira delas é a de que o Brasil reúne as características principais para ser caracterizado como Potência Regional: "(1) é parte de uma região geograficamente delimitada; (2) está pronta para assumir a liderança; (3) ostenta as capacidades necessárias para projeção de poder regional; e (4) é altamente influente em questôes regionais." (Flemes 2010a, 406). E a segunda é a de que o país não reúne as condiçōes para ser uma Grande Potência, principalmente poder militar com que possa competir com as outras grandes potências. (Flemes 2010a).

A atuação da diplomacia brasileira, segundo Flemes (2010a), é de acordo com uma potência regional, mas na busca por se tornar uma Grande Potência. No entanto, integrar a gestão do Sistema Internacional no rol das grandes potências ainda está longe de se tornar realidade. O País, porém, inicia este caminho destacando que o poder que concentra está em seu tamanho físico (recursos naturais e estratégicos), populacional (demográfico) e de sua economia, ou seja, baseado numa mescla de recursos com capacidades materiais.

Ao analisar a atuação do Brasil como potência regional nota-se, conforme Andrés Malamud (2011), que a liderança e a hegemonia regional do Brasil são duvidosas e suscitam questionamentos importantes. Malamud (2011) considera que o Brasil é deficiente em sua liderança, pois ela é exercida sem seguidores. Além disso, destaca que os principais objetivos da política externa, quais sejam a liderança regional e o ingresso no Conselho de Segurança da ONU, não são alcançados. (Malamud 2011). Destaca ainda que o País é desprovido de meios materiais para exercer liderança e tenta promovê-la, por isso, a partir de seu Soft Power ou então na forma de uma Hegemonia Consensual (Malamud 2011; Burges 2008). O Brasil apresenta ainda uma limitada capacidade de financiar a integração regional, ou seja, configurar-se como Paymaster do processo de integração sul-americana. Igualmente, as grandes desigualdades sociais e econômicas internas ao País dificultam a tomada de decisão política em prol do financiamento dos países vizinhos. A escolha por resolver problemas internos é prioridade no orçamento do País.

Como exemplos da falta de liderança do Brasil, conforme Malamud (2011), está o mau funcionamento do Mercosul e o ambiente de rivalidade e ideologia 
da Unasul, em que o Brasil não consegue fazer valer sua liderança na região. O comportamento dos "seguidores" é, portanto, errático e livre sem a adequação aos objetivos do líder. A forma de atuar do Brasil e seu novo "status" de poder suscitam reações nos vizinhos sul-americanos de forma que passam a ver o País de duas formas, segundo Malamud (2011): como um welcome paymaster e também como uma potência neocolonial. Dessa forma, mesmo que o Brasil detenha condiçōes de exercer liderança e vir a tornar-se líder, ainda não o é e não a exerce.

A capacidade de um Estado em projetar força define o tamanho do poder relativo que detém no sistema internacional, mas também os meios para efetivar sua política externa. ${ }^{3}$ A ausência de poder desse tipo para fins de uma análise sobre a capacidade de modificar e alterar o sistema internacional é relevante. Se considerarmos o caso brasileiro a partir das análises feitas pelos estudiosos da atual conjuntura externa do Brasil, há um relativo consenso sobre as limitadas capacidades militares do País. Além disso, é necessário destacar que o País ainda se encontra em estágio inicial de seu desenvolvimento socioeconômico e que desafios ou crises ainda podem estar no horizonte da economia nacional.

Como forma de visualizar que as mudanças na condução do Brasil se relacionam com mudanças estruturais, insere-se o Gráfico 1, que contém dados agregados sobre a capacidade nacional dos países ${ }^{4}$. Dele constam os dados da série histórica de distribuição relacional de capacidades materiais do BRIC+EUA de 1945 até 2007. Permite identificar que o crescimento de poder dos emergentes, em especial Índia e China, produz alteraçōes estruturais que corroboram os argumentos do realismo estrutural. Também nota-se que o crescimento econômico do Brasil não é suficiente para afetar o índice de capacidade nacional. Assim, as mudanças na política externa do País não podem ser explicadas apenas por conjunturas internas ou regionais, mas sim por remeterem-se às mudanças na estrutura do sistema internacional (Amorim Neto 2011) e que são bem "aproveitadas" pelo Brasil. (Fonseca Jr 2011).

3 A diferença entre recursos e capacidades é relevante na análise proposta. Os recursos podem ser considerados como fatores básicos do Estado (riqueza mineral, território, população), enquanto as capacidades são "recursos" operacionais (forças armadas, PIB, capacidade industrial, tecnologia). (Hill 2003).

4 O índice é composto pelos seguintes indicadores: produção de aço e ferro, gastos militares, tamanho das forças armadas, consumo de energia, população total, população urbana. 


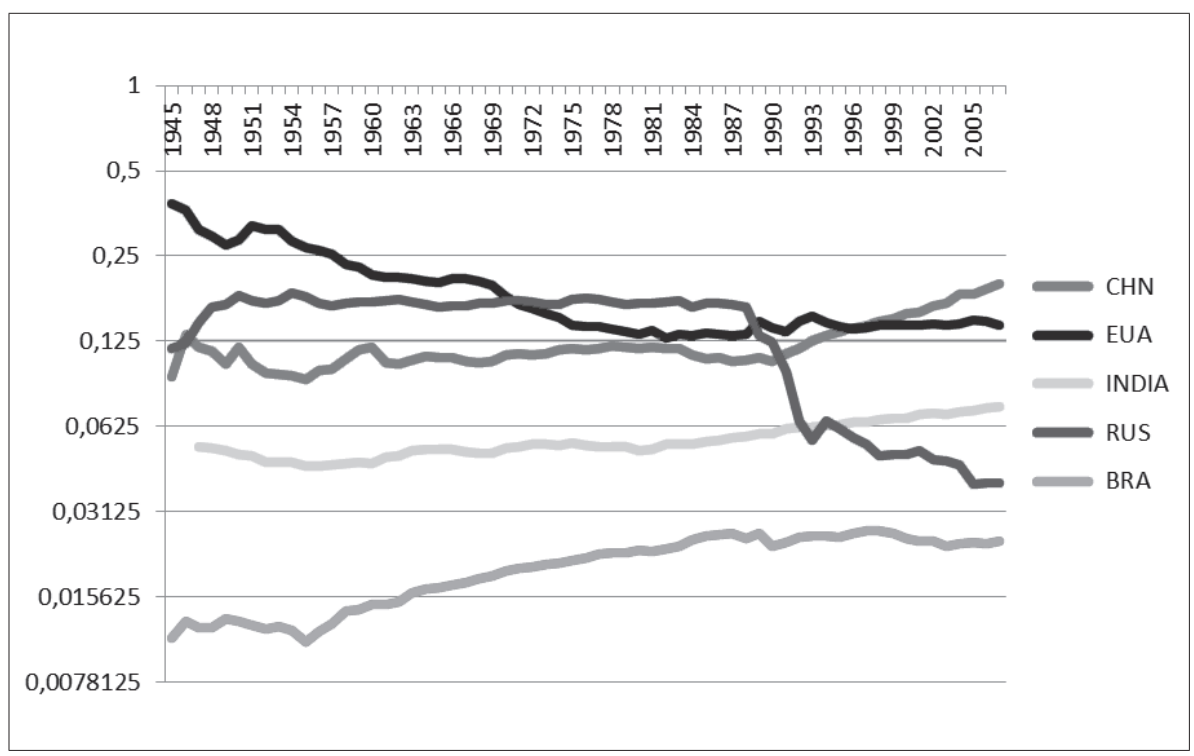

Gráfico 1. Dados CINC (Correlates of War) de BRIC+EUA.

O Gráfico 1 ilustra que a distribuição de capacidades no sistema internacional altera-se, principalmente com a queda da URSS e com a emergência da China e da Índia. Essas alterações são recentes e cabe destacar que é a partir do final da Guerra Fria que ocorrem as principais mudanças. Portanto, elas coincidem com a estabilidade política e econômica do Brasil. (Power 2010). Podemos destacar que a política externa do País é bem-sucedida na expansão global de sua atuação, aproveitando as mudanças estruturais; porém, os ganhos relativos são maiores que os objetivos, pois há uma superestimação do poder que concentra, ocasionando alguns erros de cálculo, como na recente questão da tentativa de mediação do Brasil entre Irã e EUA.

O que podemos concluir da análise da política externa recente do Brasil é que pretende atuar como grande potência, principalmente no amparo do BRICS, mas que suas capacidades reais estão mais adequadas ao nível de potência intermediária, com grandes limitações de atuação e inserção internacional. Assim, o País não dá conta de alcançar os principais objetivos de sua política externa. Dessa forma, cabe questionar que implicações derivam para o Brasil em função de deter um baixo nível de capacidades materiais ou recursos para implementar sua política externa? Para além dos efeitos regionais de inviabilizar a liderança regional ou a sua configuração como potência regional, há limitações importantes à maior participação internacional, por exemplo, na configuração como membro permanente do Conselho de Segurança da Organização das Nações Unidas (CSONU). 


\section{Desafios estruturais a uma potência emergente}

Após identificarmos o papel fundamental da estrutura do sistema internacional sobre todas as unidades, pode-se inferir que a estrutura do sistema internacional importa e condiciona os atores emergentes. (Waltz 1979; Amorim Neto 2011). É relevante destacar que as mudanças estruturais, para além das mudanças políticas na condução da agenda da política externa, abrem espaço para um maior protagonismo brasileiro na região e no mundo. No entanto, os principais desafios que podemos destacar estão relacionados com as limitadas capacidades do País, pois ao mesmo tempo em que foi "ajudado" pela redistribuição de capacidades no sistema internacional, não obteve maiores ganhos, e isso em função de não deter capacidades que permitam operacionalizar os objetivos aos quais se propóe principalmente à liderança regional ou na participação mais ativa em assuntos internacionais de poder. (Malamud 2011). Entretanto, devemos destacar que houve o interesse dos definidores da política externa do Brasil em participar da política mundial de forma diferente. (Flemes 2010a).

Responder aos constrangimentos e condicionantes estruturais faz parte do comportamento "previsto" dos Estados, em termos teóricos pelo neorrealismo e pelo realismo neoclássico, inclusive daqueles que emergem no sistema internacional e que passam a atuar no âmbito da high politics. Os desafios estruturais relacionam-se com as respostas que o País dará ao sistema internacional. Nota-se que as respostas em termos de Soft Power e no âmbito do Multilateralismo pelo País alcançam o nível global; contudo, quando a ênfase analítica é posta no lado do Hard Power (Nye 2004), a resposta do País está diretamente relacionada com a sua limitada capacidade material. Alfredo Valladão (2005) ilustra bem esse aspecto ao afirmar que enquanto o ambiente de competição internacional é Grociano, o Brasil entra no "jogo"; mas se muda para um ambiente Hobbesiano, ele sai de cena. A tese central de Valladão (2005) dá conta de uma necessária "multilateralização" do poder dos EUA entre os parceiros ocidentais da América Latina e da Europa Ocidental, pois a autonomia que buscam os Estados dessas regiōes poderá vir pelo aumento de sua responsabilidade no mundo. Ser capaz de usar a força pode ser um dos critérios na definição de coalizões de poder na transição. Isso está relacionado diretamente com as capacidades limitadas do País, que impedem sua inserção em ambientes de negociações geopolíticas globais. Conforme Fonseca Jr (2008, 125):

Para o Brasil, foi uma coincidência favorável o fato de que no momento mesmo em que no jogo de poder mundial reduzia-se a importância singular dos fatores militares (especialmente no jogo entre as potências), fomos capazes de estabilizar a nossa economia e de alcançar um grau de abertura sem precedentes nos últimos anos. [...] De outro lado, nossa capacidade de influência internacional ainda está limitada por problemas internos, a restringir estruturalmente as possibilidades de ação do Estado, que dispõe de instrumentos (econômicos, militares etc.) escassos e nem sempre plenamente mobilizáveis. 
Esse afastamento das políticas de poder pode não ser mais uma opção válida devido ao papel condicionante e constrangedor do sistema internacional sob a política externa do País. Para este autor o cenário vindouro de uma multipolaridade é benéfico ao Brasil e pode ser um cenário otimista com ganhos quando atuar na cena multilateral. Cabe notar que esse cenário é distinto do previsto pelo realismo estrutural que aqui expomos, ou seja, de uma Multipolaridade Desequilibrada, que se caracteriza por grande instabilidade internacional. (Mearsheimer 2001). Dessa forma, interpretamos como tentativa de responder aos constrangimentos estruturais o País passar a desenvolver um conjunto de açóes para minimizar essas limitaçôes econômicas e, principalmente, militares.

Como exemplos dessa nova preocupação do País, citam-se a Política de Defesa Nacional $(\mathrm{PDN})^{5}$ e a Estratégia Nacional de Defesa (END) ${ }^{6}$, que têm como objetivos dotar o País de capacidades de projeção de força militar regional e de dissuasão, mas também se vinculam a um projeto de desenvolvimento nacional e integração regional. Uma análise crítica dessas iniciativas é relevante, a fim de evitar percepções equivocadas dos projetos de incremento militar do Brasil. Ademais, um balanço crítico dos principais indicadores econômicos do País na última década complementará a análise das suas capacidades materiais.

\section{Incremento militar?}

Para iniciar o conjunto de críticas às iniciativas de incremento militar, recorreremos ao estudo de Paulo Roberto de Almeida (2010) sobre a END, pois ele afirma que há nesta uma definição de como não fazer a guerra. Para esse autor os objetivos de "desenvolvimento" suplantam as definições sobre Defesa. Não há, segundo Almeida (2010), uma definição clara dos objetivos de defesa, nem quem são os possíveis inimigos ou rivais do País. ${ }^{7}$

Um balanço crítico sobre orçamento, efetivos e equipamentos das Forças Armadas do Brasil é realizado por Eugênio Diniz (2010). Nesse estudo ele demonstra que a porcentagem orçamental do setor de defesa já é demasiado grande em relação à composição de gastos do poder Executivo do Brasil ${ }^{8}$; dessa forma, um incremento orçamental é difícil. Por conseguinte, a viabilização de grandes projetos que envolvam vultosos gastos e compras é de complicada efetivação. Os desequilíbrios entre os efetivos e os equipamentos destacam a necessidade de reequilibrar a razão entre eles, pois há, no caso do Brasil, demasiado número

5 Disponível em <https://www.defesa.gov.br/index.php/publicacoes/politica-de-defesa-nacional.html>, acessado em 30 jun. 2011.

6 Disponível em <http://www.defesa.gov.br/projetosweb/estrategia/>, acessado em 17 nov. 2011.

7 Encontra-se em fase de debate e elaboração final o "Livro Branco de Defesa do Brasil", no qual se espera que sejam definidos estes aspectos em falta na Política de Defesa Nacional e na Estratégia Nacional de Defesa.

8 Ocupa o terceiro lugar nos gastos do Poder Executivo do Brasil, atrás apenas da Previdência Social e da Saúde. (Diniz 2010). 
de efetivos para poucos equipamentos militares. Sem destacar para efeitos de contabilidade quais deles estão em funcionamento e quais estão comprometidos para o uso em combate. (Saint-Pierre 2010). A ausência de um projeto de força que oriente a elaboração política em defesa no País conduz aos equívocos destacados e à limitação da capacidade militar do País. Diniz (2010), ao comparar as Forças Armadas de Brasil, Índia, Israel e África do Sul, destaca que em diversos aspectos as forças brasileiras são as mais mal equipadas e que apresentam a pior relação entre efetivo e equipamentos militares.

Nesse sentido, podemos adicionar os acordos para o incremento tecnológico e para a produção de equipamentos militares que foram firmados recentemente. Os projetos mais destacados são os referentes ao submarino de propulsão nuclear, com a França, e os acordos bilaterais para produção de satélites e veículos de lançamento, com a China, e a compra de novos aviōes de combate com a transferência de tecnologia para o Brasil. (Cepik 2011; Flemes e Nolte 2010).

A preocupação do Brasil com segurança e o incremento de poder associam-se, nesse caso, ao fomento da cooperação regional e à criação de regimes de normas que possam dotar a região de previsibilidade e institucionalidade em matéria de defesa e segurança. A defesa passa então a ser objetivo da política externa do Brasil. Essa é outra crítica feita por Almeida (2010). João Paulo Alsina Jr. (2009), por outro lado, aborda a necessidade de o Brasil associar capacidades materiais de força à política externa.

A Estratégia Nacional de Defesa revela uma associação entre a política regional e a política de defesa do País. A defesa passa a ingressar na prioridade regional; como exemplos dessa preocupação, pode-se citar a criação da Unasul e do CDS. A primeira organização visa a promover a cooperação política entre os países da região, enquanto a segunda relaciona-se diretamente com cooperação e coordenação da defesa regional. O incentivo a uma indústria de defesa regional figura dentre os objetivos da END para promoção de vínculos de defesa e de desenvolvimento na região. Enfim, as respostas aos constrangimentos estruturais vão ao encontro de incrementar poder e buscar a segurança do Estado. Assim, ao mesmo tempo em que existem oportunidades oriundas da redistribuição de capacidades, surgem desafios importantes que ainda estão longe de serem solucionados.

\section{Desenvolvimento econômico?}

Dentre as oportunidades e desafios das mudanças estruturais, o País vê nessa transição para a multipolaridade o momentum de incrementar seu desenvolvimento nacional ${ }^{9}$. Os objetivos buscados pelo Estado brasileiro vão de acordo com os que os teóricos neorrealistas propõem, ou seja, na busca de interesses de poder.

9 O crescimento do Produto Interno Bruto do País nos recentes anos conduz os analistas do mercado financeiro internacional a inserir o Brasil dentro as economias emergentes. 
Contudo, os desafios sistêmicos ao desenvolvimento econômico do País relacionamse diretamente com a emergência dos novos atores, principalmente da China. (Cunha 2011). Destaca-se a relação que emerge na última década, pois nota-se um crescente volume de negócios entre esses países, de forma que a China supera a importância dos EUA nas exportações brasileiras.

É nesse contexto de crescimento das relações comerciais com a China que ocorre o debate sobre a reprimarização e desindustrialização do Brasil. Alguns trabalhos apontam para dados iniciais desse processo, mas não permitem afirmar que já esteja em curso a desindustrialização da economia brasileira. Segundo Oreiro e Feijó (2010), os dados referentes ao processo de desindustrialização do período recente do Brasil não dão conta de uma desindustrialização, porém apontam para um cenário "inquietante de doença holandesa" no País em longo prazo.

O Gráfico 2 demonstra as recentes mudanças no comércio exterior do País, chama a atenção ao declínio dos produtos manufaturados e ao crescimento dos básicos. Cabe destacar que a força da economia interna é que está a conduzir o desenvolvimento; portanto, essa realidade do comércio exterior reflete uma parte do conjunto da economia do Brasil. No entanto, retrata com fidelidade o modelo de inserção internacional e os desafios em termos de relações econômicas internacionais.

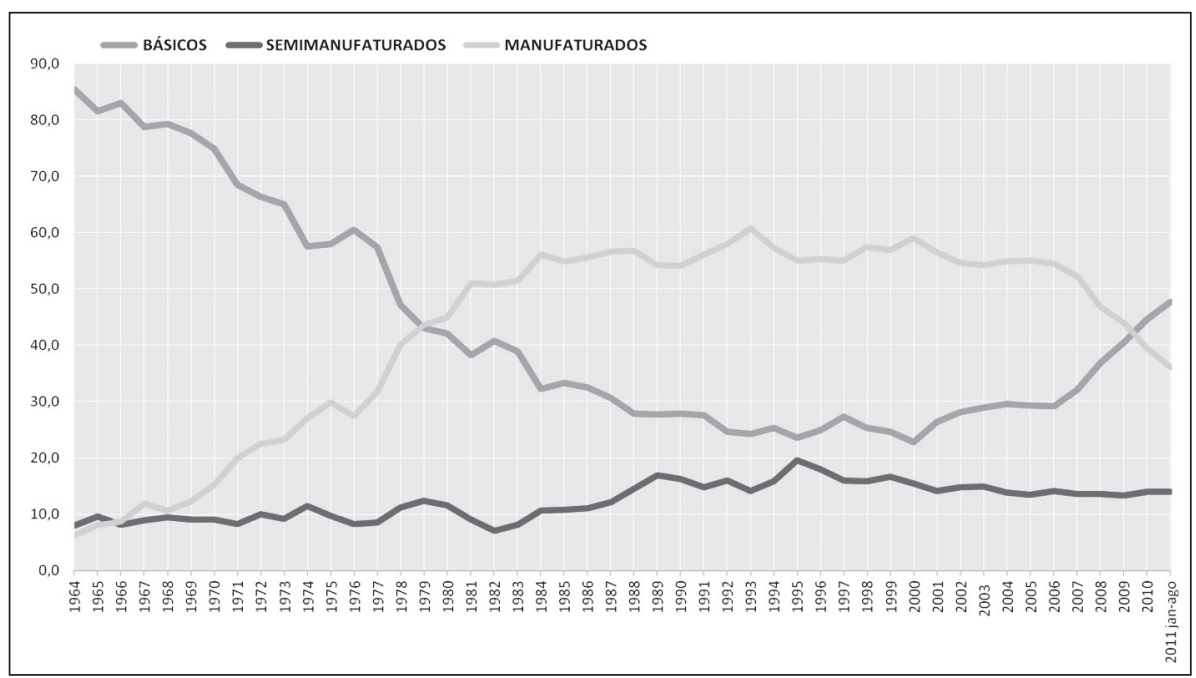

Gráfico 2. Evolução da exportação brasileira de 1964 a 2010 (em milhões de dólares). Fonte: MDIC/Brasil.

O crescimento das exportações de produtos básicos relaciona-se diretamente com fatores econômicos externos, como o aumento da demanda internacional e o preço em alta das commodities, produzindo uma tendência à reprimarização da economia do País. Isso, por seu lado, relaciona-se, portanto, com um aumento 
na demanda internacional por produtos desse tipo - principalmente a demanda chinesa -, mas também com o aumento do preço das commodities. A emergência da China provoca a redistribuição nas capacidades materiais ao redor do mundo, principalmente pela ascensão da Ásia como zona econômica com maior crescimento mundial. Essa redistribuição abre um conjunto de possibilidades aos Estados, em especial aos outros emergentes. No entanto, a emergência chinesa implica dificuldades derivadas da sua forma de inserção mundial. A demanda crescente por commodities e a inserção de bens manufaturados com preços mais baixos afetam diretamente o comércio internacional de alguns países, como o Brasil. Assim, a diversificação em novos "eixos" de inserção internacional do Brasil liga-se a essas novas dinâmicas econômicas internacionais.

Assim como a atuação em cenários geopolíticos - quer sejam regionais, quer sejam globais - implicam dificuldades ao País devido à sua limitada capacidade de projeção de força, a inserção econômica do País também é limitada, pois ele representa apenas $1 \%$ do volume mundial de mercadorias. A iniciativa BRICS representou uma grande oportunidade ao Brasil, porque é a partir dela que o País integra o jogo dos grandes, sem necessariamente sê-lo. Isso não impediu de adquirir ganhos relativos e cumprir com alguns objetivos de política externa. No entanto, consolidar os objetivos e projetos, como o status de líder regional e membro permanente do CSONU, ainda necessitam de modificações grandiosas no tamanho do poder que o País concentra e que será necessário operacionalizar para garantir seu espaço no "jogo das grandes potências".

\section{Considerações finais: Brasil - Chacal ou Cordeiro?}

Dessa forma, resta identificar quais as possibilidades de ações do Brasil nesse cenário exposto em função de suas capacidades materiais. Tomamos por base as proposiçōes de Schweller $(1994,1998)$ para identificar as possibilidades de comportamentos dos atores no sistema internacional. Para Schweller os Estados se dividem entre aqueles que mantêm o Status Quo e entre os Revisionistas da estrutura do sistema internacional. ${ }^{10}$ Dentre os status quo seekers encontram-se os Leões e os Cordeiros; dentre os Revisionistas, os Lobos e os Chacais. Os Leōes são os líderes do sistema internacional, que atuam constantemente em prol da manutenção da estrutura, impedindo que os Lobos e os Chacais modifiquem-na. Os Leões, por coerência teórica, têm comportamentos de autopreservação e de manutenção da sua posição relativa no sistema internacional. Por seu lado, os cordeiros serão as presas nesse jogo de poder. São, portanto, os atores com fracas capacidades, com recursos escassos e não estão dispostos a colocar em risco o status quo. (Schweller 1994). A imagem mais relevante para este artigo é a dos Chacais, pois são os atores

10 Devemos notar que Schweller é considerado um Realista Neoclássico Ofensivo, segundo Moure Peñin (2010). 
insatisfeitos com o status quo e tendem a aproveitar as oportunidades sistêmicas.

A categoria de Lobo refere-se àqueles Estados revisionistas que não aceitam a configuração do sistema internacional e que chegam a adotar posturas agressivas. A essas categorias comportamentais devemos somar as opções dos Estados, ou seja, o Balancing e o Bandwagoning. O equilíbrio dos interesses postulado por Schweller (1994) define que o comportamento de Balancing é esperado pelos Estados líderes, enquanto o Bandwagoning prevalece entre aqueles com menor poder no sistema internacional. Portanto, o comportamento de Balancing seria o esperado dos Leões e dos Lobos, enquanto o Bandwagoning dentre os Chacais e os Cordeiros. Em que categoria poderíamos inserir o Brasil, para fins analíticos? De acordo com o acima exposto, há uma nítida tentativa do País em promover mudanças no sistema internacional. Conforme Samuel Pinheiro Guimarães (2001), a multipolaridade deve ser o objetivo a ser buscado. Assim, os esforços em integrar o IBAS e o BRICS corroboram essa nova face da atuação política internacional. É fácil notar que não é líder nesta mudança; porém, busca proveito dela, assim o Brasil se encaixa na categoria de Chacal na atual configuração, ou seja, oscilando entre o Leão do Status Quo (EUA) e o Lobo Revisionista (China) à espera de ganhos relativos.

Não há incoerência entre práticas de Balancing e Bandwagoning, segundo Schweller (1994), pois a motivação de ganhos de poder ou de se evitar perdas no sistema internacional são as motivações básicas desses comportamentos. Assim, são previsíveis em termos teóricos os comportamentos do Brasil no sistema internacional, ora na promoção do Balancing em conjunto com os atores do Sul-Sul, China e Índia, ora no Bandwagoning ao líder - EUA. Schweller (2011) afirma que o Brasil emerge como principal ator revisionista entre os emergentes; contudo, as mudanças do atual governo Dilma em favor dos eixos tradicionais (EUA e Europa) contrapõem essa afirmação. Michel Glosny $(2010,128)$ ainda destaca os receios chineses com relação à atuação global do grupo do BRICS. Participar do grupo ocorre em resposta aos constrangimentos estruturais da unipolaridade, porém uma preocupação central é demonstrar à potência unipolar que não se trata de uma coalizão para promover o Hard Balancing.

Portanto, a estrutura do sistema internacional pode ser considerada como principal variável causal do comportamento das potências emergentes, como ficou observado a partir do caso brasileiro. No entanto, há limitações evidentes desse tipo de análise, pois dá peso demasiado à estrutura do sistema internacional em contraposição ao ambiente interno e as condicionantes que dela derivam. Entretanto, como verificamos, o País responde às condicionantes do sistema internacional por meio de uma busca por maior inserção mundial, pela tentativa de incremento de suas capacidades materiais, pelo projeto de gerir a região e pelas novas coalizões que efetua no sistema internacional. Dessa forma, esta análise pode promover um complemento às análises de política externa do Brasil, que se focam em sua maioria nas suas condicionantes internas. 


\section{Referências bibliográficas}

ALMEIDA, Paulo Roberto de. (2010) A Arte de NÃO fazer a Guerra: novos comentários à Estratégia Nacional de Defesa. Meridiano 47, vol 11, no 119, junho, pp. 21-31.

ALMEIDA, Paulo Roberto de. (2004) Relações internacionais e política externa do Brasil: história e sociologia da diplomacia brasileira. 2.ed. Porto Alegre: Ed.UFRGS. 438 p.

ALSINA JR, João Paulo Soares. (2009) O poder militar como instrumento da política externa brasileira contemporânea. Rev. bras. polit. int. vol. 52, n. 2, pp. 173-191.

AMORIM NETO, Octavio. (2007) A Política Externa Brasileira: Novos Dilemas Geopolíticos e sua Falta de Condicionamentos Domésticos. Análise de Conjuntura OPSA, n. 3, p. 1-10, mar. 2007.

AMORIM NETO, Octavio (2011) De Dutra a Lula: a condução e os determinantes da política externa brasileira. Rio de Janeiro: Elsevier.

AVILA, Fabrício Schiavo; MARTINS, José Miguel; CEPIK, Marco. (2009) Armas estratégicas e poder no sistema internacional: o advento das armas de energia direta e seu impacto potencial sobre a guerra e a distribuição multipolar de capacidades. Contexto Internacional. [online]. vol. 31, n. 1, pp. 49-83.

BURGES, Sean W, (2008) Consensual Hegemony: Theorizing Brazilian Foreign Policy after the Cold War, International Relations, Vol. 22, No. 1, pp. 65-84.

CEPIK, Marco; SCHNEIDER, Luiza. (2010) Kenneth Waltz. In: Marcelo MEDEIROS; Marcos COSTA LIMA; Rafael VILLA; Rossana ROCHA REIS. (Org.). Os Clássicos das Relações Internacionais. 01 ed. São Paulo: HUCITEC, v. 01, p. 84-109.

CEPIK, Marco. (2011) A política da cooperação espacial chinesa: contexto estratégico e alcance internacional. Rev. Sociol. Polit. vol. 19, suppl. 1, pp. 81-104.

CERVO, Amado Luiz. (2010) Brazil's rise on the international scene: Brazil and the World. Rev. bras. polit. int. [online]. vol. 53, n. spe., pp. 7-32.

CERVO, Amado Luiz. (2003) Política exterior e relaçōes internacionais do Brasil: enfoque paradigmático. Rev. bras. polít. int. [online]. vol. 46, n. 2, pp. 5-25.

COUTO, Leandro Freitas. (2007) O horizonte regional do Brasil e a construção da América do Sul. Rev. bras. polit. int. [online]. vol. 50, n. 1, pp. 159-176.

CUNHA, André Moreira. (2011) A China e o Brasil na Nova Ordem Internacional. Rev. Sociol. Polit. vol. 19, suppl. 1, pp. 9-19.

DINIZ, Eugênio. (2010) Defesa, orçamento e projeto de força: o Brasil em perspectiva comparada. In: CEPIK, Marco. (ed.) Segurança Internacional: práticas, tendências e conceitos. São Paulo: Hucitec.

ELMAN, Colin ; ELMAN, Miriam Fendius (eds.), (2003) Progress in International Relations Theory: Appraising the Field. Cambridge, MA: MIT Press.

FLEMES, Daniel. (2010a) A Visão Brasileira da Futura Ordem Global. Contexto Internacional. Vol. 32, no 2, jul-dez, 2010.

FLEMES, Daniel. (2010b) O Brasil na iniciativa BRIC: soft balancing numa ordem global em mudança? Rev. bras. polit. int. [online]. vol. 53, n. 1, pp. 141-156. 
FLEMES, Daniel; NOLTE, Detlef. (2010) Alianzas externas en armamento y defensa. Una nueva dimensión en la agenda de seguridad Latinoamericana. Foreign Affairs Latinoamérica, Vol. 10, No 1, pp. 1-13. Ene-Mar.

FONSECA JR, Gelson. (2008) Anotações sobre as condições do sistema internacional no limiar do século XXI: a distribuição dos pólos de poder e a inserção do Brasil. In: DUPAS;LAFER;SILVA (Org.) A nova configuração mundial do poder. São Paulo: Paz e Terra. pp. 105-134.

FONSECA JR, Gelson. (2011) Notes on the Evolution of Brazilian Multilateral Diplomacy. Global Governance: A Review of Multilateralism and International Organizations: JulySeptember 2011, Vol. 17, No. 3, pp. 375-397.

GLOSNY, Michael A. (2010) China and the BRICs: A Real (but Limited) Partnership in a Unipolar World. Polity, Vol. 42(1), Jan. pp. 100-129.

GUIMARÃES, Samuel Pinheiro. (2001) Quinhentos anos de periferia. Porto Alegre: Ed. UFRGS.

HILL, Christopher. (2003) The changing politics of foreign policy. Palgrave Macmillan. 376 p.

HURRELL, Andrew. (2010) Brazil and the New Global Order. Current History, Vol. 109, No 724, pp. 60-68.

MALAMUD, Andres. (2011) "A Leader without Followers? The Growing Divergence between the Regional and Global Performance of Brazilian Foreign Policy", Latin American Politics and Society, Vol. 53 No 3: 1-24.

MEARSHEIMER, John J. (2001) The Tragedy of Great Power Politics. New York: W. W. Norton.

MOURE PENIIN, Leire. (2009) El Programa de Investigación Realista ante los Nuevos Retos Internacionales del Siglo XXI. Serviço Editorial Universidad del Pais Vasco. 424 p.

NOLTE, Detlef, (2006) Potencias regionales en la política internacional: conceptos y enfoques de análisis, Hamburgo: Giga Working Papers, 30, October.

NYE, Joseph S. (2004) Soft Power. The Means to Success in World Politics. New York: Public Affairs.

OREIRO, José L.; FEIJÓ, Carmen. (2010) Desindustrialização: conceituação, causas, efeitos e o caso brasileiro. Revista de Economia Política, vol. 30, no 2, (118), pp. 219-232, abril-junho.

PECEQUILO, Cristina Soreanu. (2008) A política externa do Brasil no século XXI: os eixos combinados de cooperação horizontal e vertical. Rev. bras. polit. int. [online]. vol. 51, n. 2 pp. 136-156.

POWER, Timothy J. (2010) Brazilian Democracy as a Late Bloomer: Reevaluating the Regime in the Cardoso-Lula Era. Latin American Research Review 45.S: 218-247.

SAINT-PIERRE, Hector. (2010) A Defesa na Política Externa: dos fundamentos a uma análise do caso brasileiro. Análise de Conjuntura OPSA, n. 8, ago. pp. 1-19.

SARAIVA, José Flávio Sombra. (2010) The new Africa and Brazil in the Lula era: the rebirth of Brazilian Atlantic Policy. Rev. bras. polit. int. [online], vol. 53, n. spe, pp. 169-182.

SCHWELLER, Randall. (1994) Bandwagoning for Profit: Bringing the Revisionist State Back. International Security, vol. 19, $\mathrm{n}^{\circ}$ 1. pp. 72-107. 
SCHWELLER, Randall. (1998) Deadly Imbalances: Tripolarity and Hitler's Strategy of World Conquest. New York, Columbia University Press.

SCHWELLER, Randall; PU, Xiaoyu. (2011) After Unipolarity: China’s Visions of International Order in an Era of U.S. Decline. International Security 36.1: 41-72.

SCHWELLER, Randall. (2011) Emerging Powers in na Age of Disorder. Global Governance, 17:285-297.

SENNES, Ricardo. (1998) Potência Média Recém-Industrializada: Parâmetros para analisar o Brasil. Contexto Internacional. Vol. 20, no 2, julho/dezembro. pp. 385-413.

SOARES DE LIMA, Maria Regina. (2005) A política externa brasileira e os desafios da cooperação Sul-Sul. Rev. bras. polit. int. [online]. vol. 48, n. 1 pp. 24-59.

SOARES DE LIMA, Maria Regina; HIRST, Mônica. (2006) Brazil as an Intermediate State and Regional Power: Action, Choice and Responsibilities. International Affairs, Vol. 82, No 1, pp. 21-40.

SPEKTOR, Matias. (2010) Ideias de ativismo regional: a transformação das leituras brasileiras da região. Rev. bras. polít. int. [online]. vol. 53, n. 1 pp. 25-44.

VALLADÃO, Alfredo. (2005) A Autonomia pela Responsabilidade: O Brasil frente ao uso legítimo da força. Res-Pública, 1, 117-135.

VIGEVANI, Tullo; ROMANZINI JR, Haroldo. (2011) Pensamento Brasileiro e Integração Regional. Contexto Internacional, vol. 32, n. 2, jul-dez.

VILLA, Rafael Antonio Duarte; VIANA, Manuela Trindade. (2010) Security issues during Lula's administration: from the reactive to the assertive approach. Rev. bras. polit. int. [online]. vol. 53, n. spe pp. 91-114.

VISENTINI, Paulo G. Fagundes and SILVA, André Luiz Reis da. (2010) Brazil and the economic, political, and environmental multilateralism: the Lula years (2003-2010). Rev. bras. polit. int. [online]. vol. 53, n. spe, pp. 54-72.

WALTZ, Kenneth N. (2000) Structural Realism after the Cold War. International Security, Vol. 25, No 1, pp. 5-41.

WALTZ, Kenneth N. (1979). Theory of International Politics. New York: McGraw-Hill.

WOHLFORTH, William C. (1999) The Stability of a Unipolar World. International Security, Vol. 24, No 1, pp. 5-41.

WOHLFORTH, William C. (2009) Unipolarity, Status Competition, and Great-Power War. World Politics, 61, pp. 28-57.

WOHLFORTH, William C.; BROOKS, S.G. (2005) Hard Times for Soft Balancing. International Security, vol. 30, $\mathrm{n}^{\circ}$ 1. pp. 72-108.

WOHLFORTH, William C.; BROOKS, S.G. (2008) World out of Balance: International Relations Theory and the Challange of American Primacy. Princeton: Princeton University Press. 


\section{Resumo}

Este artigo analisa as configurações da política externa brasileira pós-2002 para relacionar os ganhos e perdas com as mudanças estruturais do sistema internacional. O intuito e realizar um balanço das capacidades materiais do Brasil, assim como dos seus desafios e oportunidades, a partir das categorias propostas por Randall Schweller. Chacal ou Cordeiro? Como se comporta o Brasil num sistema internacional em transição e quais podem ser as consequências? Ou seja, atua como chacal na busca de ganhos relativos ao seguir o ator mais revisionista (China), e como cordeiro na associação direta com a potência unipolar.

Palavras-chave: neorrealismo; Política Externa Brasileira; potências emergentes.

\section{Abstract}

This article analyzes the configurations of Brazilian foreign policy after 2002 in order to relate to gains and losses the structural changes of the international system. The aim is to achieve a balance of material capabilities of Brazil, as well as its challenges and opportunities, from the categories proposed by Randall Schweller. Jackal or Lamb? How does Brazil behave in the international system in transition, and what can be the consequences? That is, while Jackal it acts in pursuit of relative gains by following the more revisionist actor (China), and as Lamb in direct association with the unipolar power.

Keywords: neorealism; Brazilian Foreign Policy; emerging powers. 